\title{
Infiltration of neutrophil polymorphonuclear leucocytes into the endometrial stroma at the time of implantation of ova and the initiation of the oil decidual cell reaction in mice
}

\author{
C. A. Finn and M. D. Pope \\ Department of Veterinary Preclinical Sciences, University of Liverpool Veterinary Field Station, \\ Leahurst, Neston, South Wirral, Cheshire L64 7TE, UK
}

\begin{abstract}
Summary. Polymorphonuclear leucocytes (polymorphs) were found in the endometrial stroma adjacent to implanting blastocysts approximately $100 \mathrm{~h}$ after mating. Areas of uterus not containing a blastocyst had very few polymorphs. Ovariectomized mice were treated with hormones to render them sensitive to a decidual stimulus, the intraluminal injection of arachis oil. Areas of uterus responding to the oil (as indicated by the Pontamine Sky Blue reaction) showed an influx of leucocytes into the endometrial stroma between 16 and $36 \mathrm{~h}$ after the application of the decidual stimulus. The polymorphs were largely neutrophils. The injection of oil into non-sensitized uteri did not result in polymorph infiltration nor did the injection of physiological saline (which is not deciduogenic) into sensitized uteri. It is concluded that during the early stages of decidualization there is attraction of polymorphs from the blood into the stroma.
\end{abstract}

Keywords: leucocytes; polymorphs; endometrium; decidualization; implantation

\section{Introduction}

In the mouse and some other mammals, including women, the blastocyst implants inside the wall of the uterus. In response to the intrusion by the blastocyst, the tissues of the maternal endometrium respond in a characteristic manner with changes in the blood vessels and in the cells of epithelium and stroma.

The factors responsible for initiating the implantation reaction in the uterus are complex. Many facets of the reaction show similarities to inflammation and it has been suggested that the uterine response to the blastocyst has evolved from the tissue response to a foreign body (Finn, 1986). Among the early rections to a blastocyst are the Pontamine Sky Blue reaction (Psychoyos, 1961) (a measure of increased vascular permeability) and oedema of the stroma, both of which are characteristic inflammatory responses. Another characteristic early response to a foreign body is the migration of polymorphonuclear leucocytes (polymorphs) from the blood vessels into the tissues. These provide the first line of defence, in advance of the immune response.

Although there have been several reports of the presence of polymorphs in the endometrium during implantation of blastocysts (Lobel et al., 1967; Enders \& Schlafke, 1967; Potts, 1968; Smith \& Wilson, 1974), there has been no systematic quantitative investigation. In the present study we have examined the uterus of the mouse for evidence of polymorph invasion during implantation of blastocysts and during the initiation of the artificial implantation reaction to oil. The earliest time at which it is possible macroscopically to differentiate areas of the uterus where an implantation or decidual cell reaction is taking place is after the onset of the Pontamine Sky Blue reaction. This occurs during the night between the fourth and fifth days of pregnancy and about $10 \mathrm{~h}$ after the injection of oil into hormonally sensitized ovariectomized mice. 


\section{Materials and Methods}

\section{Animals}

Female mice 5-7 months of age and weighing $30-40 \mathrm{~g}$ were fed on a pelleted diet and bred and housed at $21^{\circ} \mathrm{C}$ with lights on from 14:00 to 06:00 h. This reverse daylight regimen is used to facilitate timing of ovulation and implantation in relation to the working day. For the first experiment mated females were obtained by placing 3 females with 1 male and checking each day during the first few hours of the light period for vaginal plugs. Mating in this colony occurs during the dark period with maximum mating occurring during the middle of the period. For timing purposes therefore mating was assumed to have occurred at approximately 10:00 h on the day on which a plug was found. Mated animals were autopsied $100 \mathrm{~h}$ after mating.

For subsequent experiments ovariectomies were performed on virgin mice under alphaxalone and alphadolone acetate (Saffan: Glaxovet Ltd, Uxbridge, Middlesex, UK) anaesthesia, and the animals were rested for at least 1 week before further treatment.

\section{Hormone treatment}

Oestradiol-17ß (Sigma Chemical Co. Ltd, Poole, Dorset, UK) was dissolved in arachis oil and administered by subcutaneous injection. Medroxyprogesterone acetate (Promone-E: Upjohn Ltd, Crawley, West Sussex RH10 2NJ, UK) was administered as an aqueous suspension by subcutaneous injection.

The schedule of hormone injections given to the ovariectomized mice was as follows:

All animals:

Days 1 and 2, 100 ng oestradiol-17 $\beta$

Days 3-5, no hormones

Full sensitivity:

Day 6, 1 mg medroxyprogesterone acetate

Days 7 and $8,10 \mathrm{ng}$ oestradiol-17 $\beta$

Partial sensitivity:

Day 6, $1 \mathrm{mg}$ medroxyprogesterone acetate only

(Medroxyprogesterone acetate is a long-acting progestagen; a single injection of $1 \mathrm{mg}$ maintains the uterus in a fully progestational state for at least 1 week (Finn \& Martin, 1978).)

\section{Unsensitized: \\ Intrauterine decidual stimulus:}

Intrauterine control injection: no further hormone treatment

to obtain a decidual response $0.015 \mathrm{ml}$ arachis oil was injected through the uterotubal junction on Day 8, $4 \mathrm{~h}$ after the second oestrogen injection (Finn \& Keen, 1962)

$0.015 \mathrm{ml}$ physiological saline $(0.09 \% \mathrm{NaCl})$ was injected into the uterus as above.

\section{Identification of areas responding to an implanting blastocyst or to the decidual stimulus}

At $15 \mathrm{~min}$ before autopsy animals were injected intravenously with $0.3 \mathrm{ml}$ of an aqueous $1 \%$ solution of Pontamine Sky Blue. At autopsy the uteri were inspected for blue areas and fixed after separation of the blue areas. In most of the oil-injected uteri from sensitized mice the whole uterine horn was blue and a small piece was taken from the middle.

\section{Histological techniques}

For experiments involving plastic embedding the uteri were immersed in Karnovsky's (modified) fixative overnight and then pieces embedded in plastic and $1 \mu \mathrm{m}$ sections cut in the usual way. For wax embedding the fixative used was Bouin's fluid and $8 \mu \mathrm{m}$ sections were cut. Plastic sections were stained with azure and wax sections with haematoxylin and carbol chromotrope.

Counting technique. Cross-sections of uteri were examined under the light microscope (using a $\times 50$ oil-immersion objective). The endometrium is clearly demarcated from the circular muscle around its periphery. Polymorphs in the endometrial stroma are easy to identify by the shape of the intensely-stained nuclei. In the first experiment 3 sections were cut from each uterus (at positions along the uterus such that the sections were several $\mathrm{mm}$ apart) and the polymorphs counted in the stroma. The results were analysed to compare the within-animal with the between-animal variability by analysis of variance. The latter was very large whereas the former was small (the $F$ value was 0.02 ). This indicates the importance of using large numbers of animals rather than increasing the observations from each animal.

\section{Results}

\section{Pregnant animals}

In the 8 pregnant animals examined, the Pontamine Sky Blue areas were distinct but there was little swelling of the uterus. Blue areas of the uterus were cut transversely until a blastocyst was 
found. A 1- $\mu \mathrm{m}$ section was cut near to the centre of the blastocyst, which was at the antimesometrial side of the uterus closely adjacent to the still-intact luminal epithelium. Under the light microscope it was clear that the stroma was oedematous with some evidence of crowding of the fibroblasts around the antimesometrial side of the lumen (a sign of impending decidualization). Within the stroma the number of polymorphs found in the 8 animals examined was $36,28,36,52$, $27,44,22$ and 25 (mean \pm s.e., $33 \cdot 75 \pm 3 \cdot 6$ ).

In only 5 of the 8 animals was it possible to dissect out a well-defined piece of uterus not showing a blue reaction. Transverse sections of these areas were prepared as before. The stroma was not oedematous and the polymorph counts were $1,3,4,3$ and 4 (mean \pm s.e., $3 \cdot 0 \pm 0 \cdot 54$ ). In agreement with the macroscopic appearance of the uterus there was little if any difference in the cross-sectional area of the uterus between the implantation and non-implantation areas.

\section{Ovariectomized animals}

Experiment 1. The mice were allocated to Group 1 (fully sensitized, oil injected), Group 2 (partly sensitized, oil injected) or Group 3 (fully sensitized, no oil injection). There were 5 animals in each group and they were killed $25 \mathrm{~h}$ after the oil injection. All animals were injected with Pontamine Sky Blue but only those in Group 1 responded positively. These blue areas only were sectioned whilst in Groups 2 and 3 areas of uterus were taken at random for sectioning. The results are shown in Table 1.

Table 1. Incidence of polymorphs in the endometrial stroma of ovariectomized mice (5/group) killed $25 \mathrm{~h}$ after various treatments (see text)

\begin{tabular}{lccccc}
\hline & $\begin{array}{c}\text { Priming } \\
\text { oestrogen }\end{array}$ & Progestagen & $\begin{array}{c}\text { Nidatory } \\
\text { oestrogen }\end{array}$ & $\begin{array}{c}\text { Decidual } \\
\text { stimulus }\end{array}$ & $\begin{array}{c}\text { Mean } \\
\text { counts } \pm \text { s.e.* }\end{array}$ \\
\hline Group 1 & + & + & + & + & $87.6 \pm 30.6$ \\
Group 2 & + & + & - & + & $4.1 \pm 0.47$ \\
Group 3 & + & + & + & - & $1.1 \pm 0.39$ \\
\hline
\end{tabular}

*Calculated from the average count of polymorphs in three cross-sections of uteri from each animal.

Experiment 2. Fully-sensitized mice were given an intrauterine injection of physiological saline and killed $25 \mathrm{~h}$ later. As expected none of the uteri showed a Pontamine Sky Blue reaction or swelling. Polymorph counts from these animals were very low $(1.55 \pm 0.98, \mathrm{~N}=9)$.

Experiment 3. Fully-sensitized mice were killed at various times after oil injection. As shown in Table 2 , the variability between animals was again very considerable, but leucocyte migration into the uterine stroma was high over the period from 15 to $35 \mathrm{~h}$. This is the period when the oedematous stroma is beginning to be decidualized. By $42 \mathrm{~h}$ decidualization of the stroma was extensive with only a small rim of undecidualized peripheral stroma. At this time polymorph numbers were very much reduced and when polymorphs were present they were distributed around the periphery of the stroma, they were rarely found among the decidual cells.

\section{Identification of type of polymorph}

The uteri from a group of fully-sensitized animals, into which oil had been injected and the animals killed $24 \mathrm{~h}$ later, were embedded in paraffin wax and cross-sections stained with haematoxylin and carbol chromotrope. The latter stains eosinophil granules red. Nine animals were examined and there were $59.4 \pm 9.5$ neutrophils and $4 \cdot 1 \pm 1.4$ eosinophils/cross-section of uterus. Clearly the polymorph invasion is largely made up of neutrophils. 
Table 2. Polymorph infiltration into the endometrial stroma at various times after injection of oil into the uterus of a fully sensitized ovariectomized mouse

\begin{tabular}{lcc}
\hline $\begin{array}{l}\text { Time since oil } \\
\text { injection (h) }\end{array}$ & $\begin{array}{c}\text { No. of } \\
\text { mice* }\end{array}$ & $\begin{array}{c}\text { Mean no. of } \\
\text { polymorphs } \pm \text { s.e. }\end{array}$ \\
\hline 12 & 7 & $5 \cdot 6 \pm 2 \cdot 3$ \\
15 & 9 & $16 \cdot 3 \pm 10 \cdot 0$ \\
16 & 8 & $34 \cdot 3 \pm 19 \cdot 2$ \\
18 & 9 & $37 \cdot 3 \pm 10 \cdot 8$ \\
27 & 4 & $36 \cdot 7 \pm 20 \cdot 4$ \\
32 & 7 & $106 \cdot 7 \pm 34 \cdot 4$ \\
36 & 8 & $58 \cdot 0 \pm 13 \cdot 8$ \\
42 & 12 & $11 \cdot 0 \pm 1 \cdot 6$ \\
\hline
\end{tabular}

* One section from each animal examined.

\section{Discussion}

The results with the pregnant animals demonstrate that migration of polymorphs into the endometrial stroma occurs at the time of implantation of ova in mice. The finding that the stroma in areas of uterus not containing a blastocyst contains very few polymorphs suggests that their migration into the stroma is a localized response to the implanting blastocyst. Subsequent experiments using the artificial oil decidual reaction in which differential stains were used show that the polymorphs are largely neutrophils. This differs from the findings of Lobel et al. (1967) who reported mainly eosinophils in the stroma at the time of implantation in the rat. Migration of polymorphs is found early in the decidual reaction and occurs before any clear morphological changes of decidualization can be seen. It does not occur in response to the instillation of oil when hormonal conditions are inimical to decidualization or when normal saline (which is not deciduogenic) is instilled into the uterus of a fully-sensitized animal. The endometrial stroma of uninjected uteri from fully-sensitized animals is also virtually free of polymorphs. Neither the presence of oil nor hormonal sensitization is sufficient by itself to cause migration of polymorphs.

The third experiment showed that the migration takes about $15 \mathrm{~h}$ to get under way. It occurs after the onset of the Pontamine Sky Blue reaction but at about the same time as the first appearance of the alkaline phosphatase reaction in the uterine stroma. By $42 \mathrm{~h}$ when the decidual cell reaction is well advanced the numbers of polymorphs in the stroma are very much reduced, with virtually none among the fully-developed decidual cells. The migration is very transitory and is associated with the early stages of decidualization.

The time taken for the polymorph migration to start is much longer than that taken for migration of polymorphs in response to the injection of chemotactic polypeptides into other tissues (Rampart et al., 1989). Presumably in reponse to the stimulus given to the endometrium by the blastocyst or oil, some chemotactic substances are secreted within the endometrium and then cause the migration of polymorphs, thus accounting for the delayed response.

Many chemical factors are known to act as attractants for leucocytes and possibly one or several of these is released in the endometrium upon attachment of the blastocyst to the wall of the uterus. For example, Hagamen factor (factor 12 in the blood-clotting cascade) is released on contact of negatively-charged particles with cell surfaces. This initiates the formation of kinins which are attractive to leucocytes as well as causing increased permeability in the blood vessels. Possibly blastocysts or oil provide a negatively-charged surface.

The association of polymorph migration with a normal physiological situation is very interesting. In other tissues polymorphs commonly appear as the first response to the presence of a 
foreign body, infection or trauma. Their presence in the endometrium at the start of implantation is consistent with the suggestion that the uterine reaction to an implanting blastocyst has evolved from the inflammatory reaction to a foreign body (Finn, 1986). What is perhaps more surprising is that the uterus which has not been sensitized to undergo a decidual reaction does not show an inflammatory response to the presence of the oil (no permeability changes, no polymorph infiltration).

It appears that the luminal epithelium of the partly or non-sensitized uterus does not respond to the inflammation-inducing effect of the oil. Similarly, blastocysts placed in a uterus which is not fully sensitized (as in delayed implantation) do not invade through the epithelium, whereas if they are placed in other organs (under kidney capsule, spleen, testis: Kirby, 1960, 1963) they rapidly invade and destroy tissue. Furthermore, destruction of the uterine epithelium will allow blastocysts to penetrate into the endometrial stroma of non-sensitized mice (Cowell, 1969). It appears, therefore, that the luminal epithelium of the uterus provides a barrier against inflammatory effects of foreign bodies and that sensitization for implantation is accompanied by removal of this barrier.

Whether polymorphs play any role in the development of the decidua is unknown. They produce several chemical substances (leukotrienes, for example), which might affect the progress of decidualization but at present no direct evidence for such a role has been found.

After inflammation tissues often undergo an immune response. This is accompanied by invasion by other leucocytes, especially monocytes and lymphocytes. These cells also appear during implantation and have been studied widely in connection with the enigma of why the blastocyst does not suffer from immune rejection once implanted. Whilst some lymphocytes appear early in the implantation reaction the major influx occurs later in the decidual response and follows the polymorph invasion (Kearns \& Lala, 1985).

We thank Mrs Audrey Meade for help with the preparation of the manuscript and Mr Michael Jones for care of the animals.

\section{References}

Cowell, T.P. (1969) Implantation and development of mouse eggs transferred to the uteri of non-progestational mice. J. Reprod. Fert. 19, 239-245.

Enders, A.C. \& Schlafke, S. (1967) A morphological analysis of the early implantation stages in the rat. Am. J. Anat. 120, 185-226.

Finn, C.A. (1986) Implantation, menstruation and inflammation. Biol. Rev. 61, 313-328.

Finn, C.A. \& Keen, P.M. (1962) Studies on deciduomata formation in the rat. J. Reprod. Fert. 4, 215-216.

Finn, C.A. \& Martin, L. (1978) Effects of a long-acting progestin on reproductive function in female mice. J. Endocr. 79, 235-238.

Kearns, M. \& Lala, P.K. (1985) Characterization of hematogenous cellular constituents of the murine decidua: a surface marker study. J. Reprod. Immunol. 8, 213-234.

Kirby, D.R.S. (1960) Development of mouse eggs beneath the kidney capsule. Nature, Lond. 187, 707-708.

Kirby, D.R.S. (1963) Development of the mouse blastocyst transplanted to the spleen. J. Reprod. Fert. 5, $1-12$.
Lobel, B.L., Levy, E. \& Shelesnyak, M.C. (1967) Studies on the mechanism of nidation. XXXIV Part 3, Implantation. Acta endocr., Copenh., Suppl. 123, 77-109.

Potts, D.M. (1968) The ultrastructure of implantation in the mouse. J. Anat. 103, 70-90.

Psychoyos, A. (1961) Permeabilite capillaire et decidualisation uterine. C. r. hebd. Séanc. Acad. Sci. Paris, D 252, 1515-1515.

Rampart, M., Van Damme, J., Zonnekeyn, L. \& Herman, A.G. (1989) Granulocyte chemotactic protein/Interleukin-8 induces plasma leakage and neutrophil accumulation in rabbit skin. Am. J. Pathol. 135, 21-25.

Smith, A.F. \& Wilson, I.B. (1974) Leucocytes in the luminal epithelium of the mouse uterus at implantation. J. Reprod. Fert. 38, 307-310.

Received 18 June 1990 